\title{
QUAL SUJEITO, QUAL ECOLOGIA? O SUJEITO ECOLÓGICO E AS POSTURAS IDEOLÓGICAS DO MOVIMENTO AMBIENTALISTA BRASILEIRO
}

Rosemeri Melo e Souza ${ }^{1 *}$

Quem somos? A intersecção, flutuante em função da duração, dessa variedade, numerosa e muito singular, de gêneros diferentes. Não deixamos de coser e tecer nossa própria capa de Arlequim tão matizada ou tão disparatadamente colorida quanto nosso mapa genérico. Não tem sentido, pois, defender-se com unhas e dentes um de nossos pertencimentos; o que se deve, ao contrário, é multiplicá-los para enriquecer a flexibilidade.

Michel Serres

Resumo: Este artigo analisa o conceito de sujeito ecológico e suas contribuições ao debate teórico-conceitual no amplo quadro da Educação Ambiental crítico-transformadora, hoje em disputa no Brasil e na América Latina em geral. Focaliza-se a emergência deste conceito através em várias posturas ideológicas do movimento ambientalista brasileiro. Conclui-se que a adoção do constructo de sujeito ecológico está vinculada à possibilidade de um novo horizonte humanista, a despeito das ambigüidades inerentes às orientações discursivas apresentadas ao longo do movimento ambientalista brasileiro.

Palavras-chave: Teoria Social - Interdisciplinaridade - Educação Ambiental

${ }^{1}$ Universidade Fderal de Sergipe. Professora Associada do Departamento de Engenharia Ambiental e dos PPG em Geografia (NPGEO) e em Desenvolvimento e Meio Ambiente (PRODEMA). Líder do GEOPLAN/UFS. E-mail: rome@ufs.br

*Versão revisada e ampliada da laestra de abertura do I Encontro Nordestino de Educação Ambiental ENEA realizado em Natal-RN em 2005.

Revbea, São Paulo, V. 9, N² 2: 214-224, 2014. 


\section{Introdução}

Este artigo apresenta uma análise acerca de um conceito que vem adquirindo um significativo estatuto analítico no campo teórico-analítico da Educação Ambiental no Brasil, a saber: o sujeito ecológico.

Desse modo, apresento, sem mais delongas, a vertente pela qual pretendo contribuir neste trabalho, a saber: uma necessária - e incompleta decerto - problematização a respeito de algumas questões vinculadas aos limites e possibilidades desse conceito, desde um ponto de vista dialógico, enfatizando as contradições evidenciadas no plano das posturas ideológicas do movimento ambientalista brasileiro.

O nosso percurso para este contributo tem como ponto de partida alguns delineamentos semânticos eleitos e, portanto, atribuídos aos seguintes construtos: ambiental, sujeito, ideologia e ecologia. Após tais balizamentos, seguirei rumo à compreensão das posturas ideológicas mapeadas em minhas reflexões em conjunto com meus interlocutores nas lides da pesquisa acadêmica, na esfera do intrincado, polissêmico e plural, sem dúvida, movimento ambientalista brasileiro.

Amparada em reflexões sobre as ressignificações do Humanismo no cerne dessas posturas ideológicas, enquanto formações discursivas, apresento alguns limites (filosóficos) e possibilidades (de acertos e de equívocos) da disseminação e do emprego, como dir-se-ia à moda do senso comum, "em larga escala", do conceito de sujeito ecológico a partir de diversas clivagens que tal conceito corra o risco de assumir - ou modos de endereçamento segundo analisa Elizabeth Ellsworth (2001) - no seio do plural, fragmentado e polissêmico movimento ambientalismo em formação no Brasil.

Estabelecido o percurso, rogo às musas êxito na tarefa assumida com o prazer de pensar-praticar-ressignificar a Educação Ambiental que me contagia e motiva há cerca de dez anos, desde a militância comunitária até os percursos da formação inicial e continuada de educadores, tanto em redes quanto nas tramas do cotidiano, ora formal/informal da Universidade, ora com outros tons e sabores na interlocução com coletivos sociais variados.

\section{Morte ou ressignificação do sujeito? - desafio à educação ambiental crítico-transformadora}

Trago ao debate a questão do sujeito, animada pela colocação de Serres (1994) que usei como epígrafe na abertura desse texto. Texto que se faz tessitura quando me leva a estabelecer, talvez à "queima-roupa" para alguns, nunca se sabe, que assumo a cosmovisão serriana de constituição inseparável, ou melhor, dentro da mesma rede, para a manter-me fiel à metáfora utilizada pelo próprio Serres, constitutiva da vida, da cultura e da subjetividade que o próprio autor nos desafia a deslindar: "... não existe vida humana sem ao menos um objeto...qual das três - cultura, técnica ou natureza - goza dessa função? Escolhe, se você se atreve!" 
Assumindo tal concepção, quero posicionar-me frente a um outro delineamento com profundas implicações para a Educação Ambiental: se não há vida humana sem objeto, não há homem sem história, compreendida enquanto modo de atuação sobre/com ou mesmo contra a natureza, conceito este sim, apropriado de forma bastante distinta segundo as posturas ideológicas que irei apresentar.

Assim, os adeptos da morte do sujeito e do fim do Humano encontram em minha alocução uma adversária, pois, educar significa assumir o conflito como condição dialógica existencial da vida humana, razão de uma Pedagogia da Esperança, evocando o Mestre Paulo Freire. Entretanto, tal posição - a morte do sujeito ou ainda, a banalização do humano - traz fecundas contribuições a uma compreensão da ontologia da concepção de sujeito ecológico, aspecto que irei desenvolver aliado à postura ideológica que o contém no ceme de suas formulações.

Por conseguinte, posso afirmar, à guisa de convite ao diálogo, que o Sujeito ao qual me refiro neste balizamento semântico adquire a afirmação não a partir do risco de individuação que, no limite, pode evocar a uma atomização do social, mas, ao contrário, Sujeito que se transforma e se reinventa a partir das revoluções moleculares (GUATARI), da noção de dobra advinda de Deleuze ou ainda, como enfatiza Alain Tourraine (1998) como aquele que se transforma na passagem do sujeito isolado para a relação entre indivíduos que se reconhecem como sujeitos.

Nessa contribuição de Touraine, encontro forte evocação ao sentido holístico e transformador que requer uma compreensão ampliada do ambiental, posto que tal reconhecimento implica o reconhecimento do Outro, não como um alguém em quem me descubro ou que vislumbro na sua diferença, mas como salienta Touraine, no mover-se conflituoso de "reconhecer que nós fazemos, com materiais e em situações diferentes, o mesmo tipo de esforço para combinar instrumental idade e identidade" (p.81-82). Isto colocado faz-se mister assumir que a discussão do Sujeito não pode dissociar-s da dimensão das políticas de identidade, posto haver implicações políticas nas escolhas das estratégias que os sujeitos utilizam para lidar com o mundo vivido.

Colocando de outro modo a questão: o sentido de apropriação conceitual do sujeito ecológico só se realiza na "démarche" de uma política do sujeito, oposta, de modo ontológico, portanto, à tese da "morte do sujeito", entendida no bojo do fracasso do projeto filosófico do Humanismo. Toma-se fundamental esclarecer esta assertiva posto que em muitos contextos, adeptos de segmentos da Ecologia Profunda (Deep Ecology) preconizam, em suas argumentações mais radicais, a substituição, em termos filosóficos, do Humanismo pelo Holismo, em nome de um pretenso igualitarismo terrestre. Combatendo esta perspectiva, convido um dos expoentes do neo-humanismo francês, Alain Renault (apud ALMINO, 2004). Este filósofo preconiza que, entre o holismo e o individualismo deve situar-se o humanismo, assim como entre o todo e o indivíduo, o sujeito. 
Tal posição traz implicações para a Educação Ambiental críticotransformadora já bem abordada nesta mesa e sobre a qual não vou me deter, mas que dizem respeito a uma visão do sujeito ressignificada enquanto construído-construtor sempre na tensividade indivíduo coletivo. Por conseguinte, o sentido de ambiental que insiro neste- diálogo comunga com uma perspectiva compreensiva de cunho hermenêutico e não racionalista que busca cercar de modo completo os objetos de sua reflexão, mas sim compreendê-los em sua transitividade e vestes de Arlequim para voltar a Serres.

Essa perspectiva adota a circularidade como trânsito entre sujeito e objeto, entre local e global, entre subjetividade e objetividade na tessitura do que se apreende, na prática educativa complexa como ambiental (Carvalho, 2003; Melo e Souza, 2005). Portanto, embebida e embalada nessa tradição interpretativa, atrevo-me a atribuir ao conceito de sujeito ecológico a condição de analogia explicativa, conforme preconizada por Geertz (1994), ou seja, forma de explicar desde um prisma simbólico como a formação pode engendrar um sujeito constituído por matrizes de pensamento e dentro de uma formação discursiva que traga a ecologia na sua centralidade, ou uma ecologia de fato complexa. Não a ecologia dos biólogos, reducionista e excludente, como ressaltam Bofi (1995) e Carvalho (2004), mas a ecologia engendrada no seio do movimento ecológico, na qual o ambiental desestabiliza e é construído tendo por base uma esfera pública (VARGAS, 2003).

Este construto, como tentarei demonstrar, assume a ser amalgamado e assimilado, não livre de contradições e desvios semânticos, pelas várias posturas ideológicas do movimento ambientalista brasileiro foco da próxima seção deste ensaio.

\section{Posturas ideológicas no discurso ambientalista brasileiro}

Desde um ponto de vista que visa situar a influência das visões de natureza no engendramento das tramas do ambientalismo no Brasil, tal influência se fez notar desde as inovações do estabelecimento de áreas verdes nas cidades (parques e jardins) cujo marco no Brasil foi à construção do Jardim Botânico do Rio de Janeiro Imperial, cuja inspiração remonta aos ideais de fruição da vida natural e repouso cultivados na Alemanha e Inglaterra desde meados da segunda metade do século XVII.

Destaca-se também a atuação dos naturalistas e artistas anglosaxônicos em países coloniais, como Franz Post e Varnhagem no Brasil, cuja tradição de retratar a exuberância da natureza no novo mundo pode ser recuada até a Carta de Caminha (BUENO, 2001), tendo contribuído, com a 
publicação de suas obras para o reflorescimento das sensibilidades face à natureza.

Em particular no caso brasileiro, a atuação dessas primeiras expedições de cunho naturalista proporciona/os rizomas mais distanciados no tempo derivados de uma visão romântica da natureza, ora com pinçadas dos aspectos hostis do mundo natural dos trópicos. Ora, tal concepção reifica uma atitude de dominação e distanciamento face à natureza, ainda presente no ceme de uma concepção ambientalista pautada pela busca de resultados e nitidamente orientada pelo preservacionismo restrito (DIEGUES; NOGARA, 2000).

As repercussões desses fatores ocorridos no mundo anglo-saxônico foram notáveis sobre políticos e ativistas da natureza nos Estados Unidos (EUA) onde foi criado o primeiro parque nacional para a preservação das espécies e paisagens de inestimável valor cênico, o Parque Yellowstone, em 1873 existente até hoje (SCHAMA, 1996).

Dado o ápice do industrialismo estender-se desde a segunda metade do século XIX até a primeira metade do século XX, com o auge dos modelos de acumulação capitalista baseados na produção em série e no estabelecimento de esquemas globais de produção/circulação de mercadorias denominados Fordismo- Toyotismo (Antunes, 1997), as posturas ideológicas do ambientalismo comucopiano e do tecnocentrismo foram preponderantes na esfera das negociações e práticas ambientais.

A necessidade de reconstrução econômica europeia no período posterior à Segunda Guerra Mundial ampliou a busca desenfreada por matérias-primas no mundo colonial (África, Ásia e Américas Central e do Sul), ensejando o processo de neocolonialismo ou nova partilha geopolítica do mundo, cuja tragédia socioambiental perdura até nossos dias, haja vista 0 agravamento da problemática ambiental nessas regiões do globo, sobretudo África e Ásia, com nuvens tóxicas, desequilíbrios ecológicos de toda sorte, acidentes ambientais de graves proporções, pandemias e o maior de todos os flagelos - a perpetuação do ciclo da pobreza e da apartação de seus povos (BUARQUE, 1998).

A título ilustrativo dessa postura do ambientalismo cornucopiano, ou seja, orientado por uma matriz discursiva que encara o mundo natural como mero dispensário sempre farto para atender à lógica incremental de um padrão desenvolvimentista sem preocupações - atuais nem tampouco futuras - com a dilapidação do meio ambiente vale ressaltar o modelo de exploração dilapidatório da Amazônia brasileira realizado por capitalistas transnacionais no projeto de mineração do vale dos índios Carajás denunciado de modo exemplar por Orlando Valverde (1985). 
Somente no bojo da grande crise capitalista de 1973 assumem relevância na agenda política internacional análises centradas na questão ambiental, a exemplo do primeiro relatório do Clube de Roma e sua orientação sobre a necessidade do crescimento zero como meio de equilibrar os recursos ambientais disponíveis em escala global (MEADOWS, 1997).

Nessa atmosfera onde emergiu a necessidade de estabelecer, no mínimo, limitações mais nítidas ao uso desenfreado das inovações tecnológicas, sob pena de comprometimento da qualidade da vida em termos imediatos e sua inviabilização para futuras gerações, Ignacy Sachs, conferencista convidado à Conferência preparatória da I Conferência Mundial sobre Meio Ambiente, realizada em 1972 em Forneux, Suíça, empregou pela primeira vez o termo ecodesenvolvimento, referindo-se a um tipo de desenvolvimento centrado na busca do equilíbrio no uso dos recursos ambientais visando sua conservação para futuras gerações.

Para Sachs (1994), o ecodesenvolvimento engloba tanto a preservação quando necessário devido à depleção e às ameaças globais sobre os recursos ambientais - quanto à conservação, apoiada em formas de uso racional do ambiente e consiste na atitude de promover um desenvolvimento sócioeconômico eqüitativo, através de estratégias ambientalmente adequadas e suportáveis a nível ecológico.

$\mathrm{Na}$ sociedade brasileira, Maurício Waldman (1992) situa como influências impulsionadoras ao início das lutas ambientalistas de cunho conservacionista, os movimentos de contracultura dos anos sessenta ocorridos na Europa e nos EUA, sobretudo hippies e ativistas políticos contra a Guerra do Vietnã, cujo slogan "Faça a Paz, não Faça a Guerra", se tomou emblemático daquela geração e da redução do consumismo nos anos setenta, intitulado "Small is Beautifull", cuja obra de Schumaker (1988) foi traduzida em português como "Importante é ser pequeno".

O mesmo autor salienta que, durante o período ditatorial (1968-1983) mesmo todo o aparato de censura aos meios de comunicação de massa, não impediu o surgimento e atuação de grupos centrados na luta ecológica, sobretudo em São Paulo, Rio de Janeiro e em Porto Alegre.

Aliás, a respeito da disseminação de idéias ambientalistas de modo mais amplo na sociedade brasileira vale resgatar que, em 1982, é realizada a primeira telenovela que trouxe com eixo central, preocupações ambientalistas. Intitulada "O Grito" e ambientada na capital paulista, essa produção da Rede Globo alertava para a necessidade de reduzir a poluição ambiental nas grandes cidades, desde a faixa-título da abertura da novela, "Salve o Verde" (ALENCAR, 2003).

É claro que a veiculação dessa novela nos estertores da ditadura militar sinalizava um período de distensão das relações entre dirigentes políticos e mídia, no tocante à censura, mas também não se pode esquecer de assinalar tal iniciativa, exibida no tardio horário das 22 horas, como fruto das pressões 
sociais internas e externas em matéria de meio ambiente, às quais a sociedade brasileira não poderia ficar imune.

Em meados dos anos 80, começou a surgir no Brasil um tipo de ambientalismo distinto do preservacionista, mais ligado às questões sociais. Surgido no bojo da redemocratização do país, logo após o fim da ditadura militar, caracteriza-se pela crítica ao desenvolvimento altamente concentrador de renda e destruidor da natureza que teve seu apogeu nesse período.

O ecologismo social ou ambientalismo camponês é incorporado por seringueiros amazônicos, pelo Movimento dos Povos Atingidos por Barragens (MAB), por movimentos indígenas e de pescadores que começam a influenciar uma nova forma de ver a conservação ambiental, propondo a participação das comunidades no planejamento e na gestão das Unidades de Conservação (BREDARIOL; VIEIRA, 1991).

A destacada participação brasileira em matéria ambiental teve sua culminância com a realização da Conferência Rio - 92, fruto de uma participação da diplomacia nacional incisiva ao longo dos últimos trinta anos, em termos de cooperação e de proposição de mecanismos ambientais internacionais a partir da ótica e das necessidades do Cone Sul.

No âmbito da ECO-92, um fórum mundial de ONG's paralelo à Rio 92, obteve maior visibilidade uma rede de grupos ambientalistas brasileiros cujas matrizes teóricas remetem ao pensamento holístico ainda que nem sempre tenham definições específicas de suas lutas e demandas a partir de uma clara compreensão de suas inspirações teóricas.

Tais grupos ambientalistas traçam como foco de suas preocupações, a adoção de estilos alternativos e menos degradantes de vida, a redução dos níveis de consumo, sobretudo em suas investidas junto a populações das grandes cidades bem como merecem destaque suas iniciativas de estabelecimento de mecanismos de mercados pautados por uma ética solidária basilar a sustentabilidade, como o mercado solidário, com seu sistema de certificação baseado em princípios éticos rumo à produção e consumo sustentáveis.

Também expressando vinculação com os reflexos da Rio-92, toma-se evidente desde a década de 90 do século XX, a emergência de atitudes ambientalmente orientadas no seio do empresariado nacional. Todavia, é bom salientar que tais iniciativas não visam romper com os ditames do capital, mas de modo contraditório, adequar-se aos novos padrões de competitividade global, ensejando uma orientação adotada por parte do mundo empresarial em ações tais como a criação do CEBDS (Conselho Empresarial Brasileiro para o Desenvolvimento Sustentável) visando orientar ao empresariado como implementar medidas e sistemas de certificação ambiental exigidos internacionalmente (ALMEIDA, 2002).

Ora, teria por isso o empresariado brasileiro incorporado em graus 
levarmos em consideração não apenas o incremento das iniciativas de projetos socioambientais desenvolvidos e/ou patrocinados por empresas nos últimos quinze anos bem como o desencadeamento de programas voltados à melhoria de performance ambiental nos mais variados segmentos empresariais, em busca da ecoeficiência, como visão da sustentabilidade nos negócios.

Sem sombra de dúvida, ainda há um fértil terreno de pesquisas e estudos no sentido de estabelecer um marco analítico coerente para a adoção do "capitalismo verde" pelo setor produtivo do Brasil, contudo, isto foge ao escopo desta contribuição.

Assim, espero ter rompido com a falsa relação entre informal-formal ao tematizar como estas posturas ideológicas mesclam-se em todos os segmentos das ações e das formulações teóricas da Educação Ambiental. Afinal de contas, esta acontece como fenômeno, nas escolas, nos mais diversos espaços, com orientações discursivas que oscilam desde uma concepção ingênua até concepções progressistas e. engajadas no contexto do pensamento social.

\title{
(Im)possibilidades de apropriação do constructo de sujeito ecológico pelos movimentos ambientalistas no Brasil
}

Nesta seção, esboçarei, sob a forma de questionamentos lapidares, três (im)possibilidades para da apropriação desse construto pela cena ambientalista brasileira:

\begin{abstract}
A primeira se configura quando os excessos destrutivos da natureza engendrados pelo modelo hegemônico de produção da vida social ameaçam a vida planetária, defensores do ecologismo estreito e orientado pelo Biocentrismo argumentam, do ponto de vista filosófico, a morte da razão como base para alicerçar um ódio irracional pelos avanços da civilização.
\end{abstract}

A esse respeito, Luc Férry (1992) evidencia que, mesmo em nome do humanismo, tal postura de sobrepujamento ideológico do mundo natural pode suscitar uma banalização do humano posto sua inserção numa ordem comum, descaracterizadora da condição de subjetividade do humano diferenciada em relação às demais espécies (COMTE-SPONVILLE, 1999). Quais as implicações possíveis desse argumento para a adoção do conceito de sujeito ecológico? Sob o prisma da postura ideológica de orientação discursiva biocentrista, poderá resultar em uma incorporação desvinculada da matriz semântica fundamental que á a condição histórica de sujeito, passando a ser este apenas um termo complementar ao Ecológico.

A segunda (im)possibilidade pode ser evocada a partir do desenraizamento do ecológico que pode, no extremo da postura tecnocêntrica, ser confundido com condições de adequação dos empreendimentos, na vertente do Capitalismo Verde (Green Capitalism). Nesta derivação, tanto a 
noção de Sujeito passa a ser confundida semanticamente com elemento do sistema quanto à conceituação de Ecologia tende a ser mistificada como regulação de fatores do meio físico, passíveis de gerar incômodos custos ambientais. Neste contexto, sujeito ecológico pode ser apropriado com o sentido explicativo de regulador/ orientador de processos, ou seja, no máximo, alguém - individual ou em grupo-dotado de condições dei usando seus conhecimentos técnicos, amortecer processos de enfrentamento, tornado, por via perversa, protagonista das ações ambientalistas de interesse corporativo. Seria esta uma apropriação que nós, educadores ambientais, poderíamos legitimar a despeito de nossas preocupações com a esfera pública da Educação Ambiental, por descuido no diálogo profundo com a teoria e a ação política dos atores sociais?

Em terceiro lugar, penso que uma outra (im)possibilidade de desvio conceitual da adoção irrefletida do sujeito ecológico pode ser vinculada à postura antropocêntrica. Esta, ao reivindicar um estatuto privilegiado do Humano face aos demais seres planetários, evoca a possibilidade de indução de uma ênfase desproporcional ao Sujeito em contextos de conflitos socioambientais, esquecendo-se de trabalhar a dialogia do sujeito como construtor/construído de/em sua materialidade relacional com o meio.

Daí tal sobrevalorização do sujeito poder acarretar um empobrecimento da compreensão de outras racionalidades situadas além do humanismo. Isto me leva a formular a você um novo convite ao repensar a ontologia do sujeito ecológico: não seria necessário recolocar enquanto bases ontológicas desse conceito orientadas por um horizonte Humanitarista devido às ambigüidades e contradições das posturas ideológicas do ambientalismo brasileiro?

Um Humanitarismo calcado na urgência e na compaixão mesmo que venha a instaurar-se apesar dos homens como salientam André ComteSponville e Luc Férry?

Dentro de um pensamento eco-sistêmico talvez o conceito de sujeito ecológico possa ser reapropriado sem tantos riscos de antinomias, nem relacionadas ao primado do sujeito, nem referidas a uma acepção de ecologia sacralizada ou (des)humanizada, sem incorrer nos riscos ontológicos e políticos que propiciaram assinalar as imprecisões abordadas neste trabalho. Mas isto é tema para outro debate, ainda por realizar.

\section{AGRADECIMENTOS}

Ao Conselho Nacional de Desenvolvimento Científico e Tecnológico (CNPq), pela concessão de Bolsa de Produtividade em pesquisa à autora. 


\section{REFERÊNCIAS}

ALENCAR, M. A Hollywood Brasileira: panorama da telenovela brasileira. Rio de Janeiro, Editora SENAC, 2003.

ALMEIDA, F. O Bom Negócio da Sustentabilidade. Rio de Janeiro, Nova Fronteira, 2002.

ALMINO, J. Naturezas Mortas:- a filosofia política do ecologismo. Rio de Janeiro, Francisco Alves, 2004.

ANTUNES, R. Adeus ao Trabalho? São Paulo, Cortez, 1997.

BOFF, L. Ecologia: grito da terra, grito dos pobres. São Paulo, Ática, 1995.

BUARQUE, C. Memorial de Livre Docência. Brasília, UNB, 1998 (mimeo).

BUENO, E. Terra à Vista! As aventuras do descobrimento do Brasil (vol. I). São Paulo, 33 ed., Companhia das Letras, 2001.

CARVALHO, I.C.M. "Os sentidos de "ambiental: a contribuição da hermenêutica à pedagogia da complexidade". LEFF, H. (org.). A Complexidade Ambiental. São Paulo, Cortez, 2003, pp. 99-120.

CARVALHO, I.C.M. Educação Ambiental: a formação do sujeito ecológico. São Paulo, Cortez, 2004.

COMTE-SPONVILLE, A.; FÉRRY, L. A Sabedoria dos Modernos. São Paulo, Martins Fontes, 1999.

ELLSWORTH, E.. Modos de endereçamento - uma coisa de cinema; uma coisa de educação também. In: SILVA, T. T. Nunca Fomos Humanos: nos rastros do sujeito. Belo Horizonte, Autêntica, 2001, pp. 9-76.

FÉRRY, L. Le Nouvel Ordre ecologique. Paris, Gallimard, 1992".

GEERTZ, C. A Interpretação das Culturas. Rio de Janeiro, Jorge Zahar, 123 ed.,1994.

MEADOWS, D. The Limits of Growth. In: NELISSEN, N., STRAATEN, J.V.D.; KLINTERS, L. (eds.). Classics in Environrnental Studies: An Overview of Classic T exts in Environrnental Studies. Utrecht: International Books, 1997, pp. 195-198

MELO e SOUZA, R. Representações Discursivas e Visões de Natureza no Pensamento Ambientalista Brasileiro. Aracaju,TOMO, ano V, $n^{\circ}$ 5,2004, pp. 99-120. (ISSN 15174549).

MELO e SOUZA, R. "Educação Ambiental e Complexidade". BERGER, M. A. (org.). Anais do $11^{\circ}$ Encontro Regional de Educação-V Semana de Educação. Aracaju, FAP/SE, 2005, pp. 187-195.

SACHS, I. "Estratégias de Transição para o século XXI". BURSZTYN, M. (org.). Para Pensar o Desenvolvimento Sustentável. São Paulo, Brasiliense, 1994, pp. 22-31.

SCHAMA. S. Paisagem e Memória. São Paulo, Companhia das Letras, 1996. 
SCHUMAKER, A. O Importante é Ser Pequeno. São Paulo, Makron Books, 1988

TOURAINE, A. Igualdade e Diversidade: o sujeito democrático. Bauru, EDUSC, 1998, pp. 81-104.

VALVERDE, O. Carajás: Planejamento da Destruição. São Paulo, Cortez, 1985.

VARGAS, J.O. Pedagogia Crítica e Aprendizagem Ambiental. In: LEFF, E. (org.). A Complexidade Ambiental. São Paulo, Cortez, 2003, pp. 121-130.

WALDMAN, M. Ecologia e Lutas Sociais no Brasil. São Paulo, Contexto, 1992 